\title{
Epidemiology, Clinical and Complications Profile of Diabetes in Saudi Arabia: A Review
}

\author{
Tarik A. Elhadd,* Abdallah A. Al-Amoudi,* Ali S. Alzahrani† \\ From the *Department of Medicine, King Faisal Specialist Hospital and Research Center, Jeddah and the tDepartment of Medicine, King Faisal \\ Specialist Hospital and Research Center, Riyadh
}

Correspondence and reprint requests: Tarik A. Elhadd - Department of Medicine · King Faisal Specialist Hospital and Research Center · PO BOX $40047 \cdot$ Jeddah 21499·Saudi Arabia · tarikelhadd58@gmail.com · Accepted for publication May 2007

Ann Saudi Med 2007; (27)4: 241-250

Diabetes mellitus is emerging as a major public health probelm in Saudi Arabia in parallel with the worldwide diabetes pandemic, which is having a particular impact upon the Middle East and the third world. This pandemic has accompanied the adoption of a modern lifestyle and the abandonment of a traditional lifestyle, with a resultant increase in rates of obesity and other chronic non-communicable diseases. The indigenous Saudi population seems to have a special genetic predisposition to develop type 2 diabetes, which is further amplified by a rise in obesity rates, a high rate of consanguinity and the presence of other variables of the insulin resistance syndrome. We highlight the epidemiology, clinical and complications profiles of diabetes in Saudi people. Diabetes is well studied in Saudi Arabia; however, there seems to be little research in the area of education and health care delivery. This is of paramount importance to offset the perceived impact on health care delivery services, to lessen chronic diabetes complications, and to reduce the expected morbidity and mortality from diabetes.

$\mathrm{T}$ he world is witnessing a diabetes pandemic. The resource burden of the pandemic will fall primarily on developing countries. ${ }^{1}$ It is expected that the estimated number of patients with diabetes of 150 million in the late 1990s will reach 230 million by 2010 and will rise further to 300 million by $2025 .{ }^{2}$ Such a dramatic increase will have a significant impact on the meager health resources of the developing countries, as diabetes is a chronic disease with devastating complications, including premature atherosclerotic cardiovascular diseases, sight-threatening retinopathy, renal failure and neuropathic diseases. The Kingdom of Saudi Arabia has a relatively young population whose lifestyle has witnessed major changes in the last four decades. A significant rise in diabetes prevalence has accompanied these changes in lifestyle. In the late 1970s and early 1980s diabetes was not considered a commonly encountered medical diagnosis in Saudi Arabia even in high-risk groups, ${ }^{3}$ and among the male Saudi population the prevalence of diabetes was not different from other parts of the world. ${ }^{4}$ However, this seems to have changed dramatically in the last two decades, as the prevalence of diabetes in Saudi Arabia is now one of the highest in the world.,6
Unique genetic and physiological characteristics of Saudis may explain in part the dramatic rise in the prevalence of diabetes. Diabetes mellitus, especially type 2 is a polygenic disorder and the high consanguinity rate among Saudis may be playing a significant role in its prevalence. ${ }^{7}$ Furthermore, Saudi Arabs have been reported to absorb glucose more rapidly than native African people from $\mathrm{Zambia}^{8}$ In addition, the accompanying change in dietary habits in the last three decades, with regular consumption of large quantities of high caloric content food coupled with adoption of more sedentary lifestyle and abandonment of the traditional nomadic way of life has led to high obesity. Obesity is a well-known and strong risk factor for diabetes, especially in high-risk population.

For this review, we studied the published literature on diabetes in Saudi Arabia with the aim of getting a global picture of the condition at a time when diabetes is having an adverse effect on health care delivery. We hope the review will be a useful and comprehensive source on the subject for researchers, academics and clinicians who care for the increasing number of patients, and help health care providers curb the tide of the diabetes epidemic. We searched available articles published 
in Medline primarily by using the key words 'diabetes mellitus' and 'Saudi Arabia' up to the time of writing of the article. We covered the epidemiology, clinical and complications profile. We also highlight any specific features that may be rather unique to diabetes in Saudi Arabia or the Middle East.

\section{Epidemiology of Diabetes in Saudi Arabia}

Table 1 summarizes the various epidemiological studies that were published in Medline between 1982 and 2004. The first study by Bacchus et al $(1982)^{4}$ studied a small number of patients and included only male civil service subjects from a small rural area outside Riyadh in the Central region. The study showed a prevalence of $2.5 \%$ and despite its several limitations the study highlights important features. About $65 \%$ of those with diabetes were overweight, and the quoted prevalence is higher than that reported by a similar study reported from India around the same time (1.6\%). The next study, a singleauthored study published in 1986, involved a small group of male and female subjects. ${ }^{10}$ It had the same flaws of involving a small number of subjects, only those from a rural area in the Western part of Saudi Arabia. ${ }^{9}$ However, it indicated the rising rate of diabetes, quoting a prevalence of $4.3 \%$, and showing in addition, high obesity rates among the diabetic subjects (42\%) compared with controls (28\%). It also showed that diabetes was more common among affluent subjects. The next study was also a single-authored study by Anukote. ${ }^{11}$ It shares the same flaws, i.e., a relatively small number of subjects not representative of the whole population. No females were studied; it included only university staff from Riyadh (an urbanized population). Its main advantage is that it confirmed the trend of a rising diabetes prevalence $(6 \%)$.
The study by el-Hazmi et al (1996) ${ }^{12}$ was devoid of the many limitations of the previous studies. It involved a large number of subjects (23 493) and both sexes of the age group 2-70 years were included. It gave for the first time a prevalence rate of type 1 diabetes $(0.21 \%)$ and of impaired glucose tolerance (IGT) $(0.715 \%)$, in addition to an overall prevalence of type 2 diabetes (4.99\%). Furthermore, it showed gender difference in diabetes prevalence ( $4.5 \%$ for females and $5.5 \%$ for males). It also pointed to the rise in prevalence of type 2 diabetes and IGT with age, reaching $17 \%$ and $12 \%$ for the former and $1.3 \%$ and $2.2 \%$ for the latter for males and females $>30$ years of age, respectively. In a follow-up report published in the year 2000 by the same authors, ${ }^{13}$ the prevalence of diabetes in males was $9.7 \%$ and in females $7 \%$ in a subset group of their original cohort who were $>14$ years of age. The highest prevalence of diabetes was among subjects from the northern region of Saudi Arabia. They also showed that there was a parallel rise in obesity rates with a higher rate in females $(20 \%)$ vs males $(13 \%)$.

A report of the household survey for chronic metabolic diseases by Al-Nuaim ${ }^{5}$ (Table 1 ) was able to map out age and gender differences in diabetes prevalence in both urban and rural areas. The prevalence of diabetes among females was $14 \%$ and $9 \%$ and that among males was $12 \%$ and $7 \%$, from urban and rural areas, respectively. The prevalence of diabetes in urban male populations in the age group $15-20$ years was $2 \%$, increasing dramatically to $49 \%$ in the female age group 51-60 years. By contrast, the corresponding prevalence of diabetes in rural areas was $1 \%$ and $29 \%$ in the same groups. The study confirmed a higher prevalence of obesity among urban females. The study also showed that age, obesity and a family history of diabetes was more common in those with diabetes. The main limitation of this study (by

Table 1. Epidemiological studies of diabetes in Saudi Arabia, 1982-2004.

\begin{tabular}{|c|c|c|c|c|c|c|c|}
\hline Study & Year & No subjects & Urban & Rural & Method & Prevalence & Comments \\
\hline Bacchus et al $\left.\right|^{4}$ & 1982 & 1385 & No & Yes & OGTT & $2.5 \%$ & Only males \\
\hline Fatani ${ }^{10}$ & 1987 & 5222 & No & Yes & RBG/OGTT & $4.3 \%$ & Only males \\
\hline Anokute ${ }^{11}$ & 1990 & 3158 & Yes & No & Urine / FBG & $6.0 \%$ & \\
\hline el-Hazmi et al ${ }^{12}$ & 1996 & 23493 & Yes & Yes & OGTT & $5.0 \%$ & \\
\hline \multirow[t]{2}{*}{ Al-Nuaim ${ }^{5}$} & 1997 & 13177 & Yes & Yes & $\mathrm{RBG} / 0 \mathrm{GTT}$ & $12.0 \%(\mathrm{M}), 14.0 \%(\mathrm{~F})$ & Urban \\
\hline & & & & & & $7.0 \%(\mathrm{M}), 9.0 \%(\mathrm{~F})$ & Rural \\
\hline el-Hazmi ${ }^{13}$ & 2000 & 15493 & Yes & Yes & OGTT & $9.7 \%(\mathrm{M}), 7.0 \%(\mathrm{~F})$ & \\
\hline Al-Nozha ${ }^{6}$ & 2004 & 16817 & Yes & Yes & FBG & $23.7 \%$ & $\begin{array}{c}\text { Overall, age } \\
\text { above age } 30 \text { yrs }\end{array}$ \\
\hline
\end{tabular}

FBG: fasting blood glucose, OGTT: oral glucose tolerance test, RBG: random blood glucose. (M): male, (F): female. 
today's standard) is that it used random blood glucose as a screening method so a significant number of subjects with diabetes might have been missed. However, at the time of the study WHO recommended using the random blood glucose as the tool for use in epidemiological studies. In a further paper by the same author, the diabetic group had more abnormalities of lipoprotein profiles, which is further amplified by overweight and obesity, thus confirming a link in the various components of insulin resistance syndrome in Saudi Arabs. ${ }^{14}$

The latest national epidemiological survey by $\mathrm{Al}$ Nozha et al (2004), ${ }^{6}$ like the report by Al-Nuaim, has the major advantage of being representative of the whole population, in addition to using a lower cut off value for fasting blood glucose as the screening method, according to latest $\mathrm{ADA} / \mathrm{WHO}$ diagnostic criteria. However, its major weakness is that it only screened subjects older than 30 years of age, so the quoted overall prevalence rate $(23.7 \%)$ may have been artifactually increased. It also confirmed the effect of urbanization, with a higher rate in urban (25.5\%) vs the rural areas (19.5\%).

In summary, all published epidemiological studies, despite the major limitations of the earlier ones, have pointed to an exponential rise in diabetes prevalence coupled with a parallel rise in obesity rates. It is an irony that in the Al Nuaim study the areas of least economic development (the southern region) have the least prevalence of diabetes despite a higher consanguinity rate, suggesting that environmental factors are far stronger than genetic factors in the dramatic rise of diabetes prevalence. Also, several of the studies confirmed the effects of urbanization and the concomitant parallel rise in obesity rates, both of which may have played a significant role in the rise in diabetes prevalence.

\section{Specific Diabetes Syndromes}

\section{Type 1 diabetes mellitus}

The main study that examined the prevalence of type 1 diabetes at a population level was that by el-Hazmi et al (1996)..$^{12}$ This study included about 8000 children younger than age 14 years and the prevalence of type 1 diabetes was reported as $0.017 \%$, with females showing more preponderance. An earlier study involved only 110 children from a single centre in Riyadh ${ }^{15}$ who were diagnosed and followed up between 1985-1989. This study showed a mean age of onset of diabetes of 5.9 years, with $30 \%$ of the cohort less than 3 years of age; $31 \%$ of the children were from first-degree consanguineous marriages. Another small study by Kulyate and Narchi $(2000)^{16}$ from the Eastern Province showed a significant increase in the incidence of type 1 diabetes between
1986 and 1997. The increase was mainly in girls and in those older than age 10 years. In the study by Fonseca et al (1985), ${ }^{17}$ the prevalence of type 1 diabetes among a cohort of 200 diabetic patients attending their hospital was $3.5 \%$ based on the presence of ketonuria, low insulin and C-peptide and the continuous need for insulin therapy. However, the same group in a later study ${ }^{18}$ involving a larger number of patients and using the criteria of a previous episode of ketoacidosis plus the use of insulin to control hyperglycemia or the onset of diabetes below age 15 years, found a prevalence of type 1 diabetes of $11.7 \%$, which is very much in accord with the prevalence of the disease from most parts of the world.

The HLA haplotype of class II DQB1 0201/0202 -DR104 was found to be associated with type 1 diabetes in Saudi patients whereas the presence of DPB1-0401 is protective against the disease, suggesting that the haplotype DR4 confers risk of the disease in the same way it does in other population groups. ${ }^{19}$ Immune markers for endocrine disease were assessed in a group of diabetic children and normal controls by Abdullah et al ${ }^{20}$ Of the Saudi diabetic children, $14.6 \%$ were positive for islet cell antibodies vs $2.2 \%$ of the normal controls. Of interest, $56 \%$ of those tested at the onset of diabetes were positive for those antibodies. In the same cohort, $8.8 \%$ were positive for antithyroid antibodies and $9.3 \%$ were positive for parietal cell antibodies, but none had anti-adrenal antibodies. The incidence of polyendocrine deficiency syndrome is not known, but in a case report, three members of the same family had Schmidt syndrome. ${ }^{21}$

\section{Other types of diabetes}

A unique association of diabetes in Saudi children was found with thalassemia major, a condition that is rare in Caucasians. ${ }^{22}$ The prevalence of diabetes was high among those thalassemic children, which was related primarily to iron overload in the liver and pancreas associated with either hypo- or hyperinsulinism. A peculiar and previously undescribed syndrome of neonatal diabetes mellitus, congenital hypothyroidism, hepatic fibrosis, congenital glaucoma and polycystic kidneys was described in two siblings (of 4) of a Saudi family. ${ }^{23}$ The diabetes was found to be of non-autoimmune origin. Another unusual syndrome of diabetes mellitus, hypogonadism, with other abnormalities, was reported in six members of the same Saudi family. ${ }^{24}$ The high consanguinity rate among Saudis may prove to be crucial in such syndromes.

\section{Gestational diabetes mellitus}

Nearly three decades ago diabetes complicating pregnancy or pregestational diabetes was occasionally en- 
countered. ${ }^{3}$ A decade later this has changed dramatically. A study that screened 210 women using the $75-\mathrm{g}$ oral glucose tolerance test after 28 weeks of gestation revealed that $19.3 \%$ had gestational diabetes. ${ }^{25}$ The overall prevalence in this study was $10.3 \%$ on followup OGTT. Mwambingen et al $(1988)^{26}$ reported that gestational diabetes is particularly common in grandmultiparae. Khawaja et al (1989) ${ }^{27}$ confirmed the earlier studies and showed an overall incidence of gestational diabetes of $11 \%$, which is primarily influenced by parity and age. In a review of prenatal care in primary care health services in the Eastern province of Saudi that included 10594 women the prevalence of diabetes among those women, was found to be $17 \%{ }^{28}$ Offspring of Saudi diabetic mothers have a higher rate of infant morbidity compared to those born to non-diabetic mothers, ${ }^{29}$ and this is characterized by excess macrosomia and operative delivery. ${ }^{30}$ On the other hand, perinatal mortality was shown to be higher in the offspring of the diabetic mothers compared to those without diabetes. ${ }^{31}$ There was no difference in perinatal complications in those born to mothers with pregestational and those whose mothers have gestational diabetes. ${ }^{32}$

A report by Narchi and Kulyate showed a high prevalence of Down syndrome in infants born to Saudi mothers with gestational diabetes. ${ }^{33}$ All affected children had trisomy 21 and there was no age difference between those who had children with Down syndrome and those who did not.

In summary, there is a parallel rise in the prevalence of gestational diabetes in common with the trend for rise in type 2 diabetes and this is associated with significant morbidity and mortality. However, other correlates for a rise in prevalence, like family history and obesity, has not been characterized by those studies. More data is needed in this area.

\section{Maturity onset diabetes of the young}

To date only few reports have pointed to the presence of this specific type of diabetes in Saudi Arabs. ${ }^{12,17}$ ElHazmi et al (1996) postulated that the condition was present in 13 children below age 14 years with diabetes whose diabetes did not require insulin therapy to control glycemia, and they had other members in the family who suffered from diabetes, but no scientific data or case report confirmed this. ${ }^{12}$

Type 2 diabetes, insulin resistance syndrome, metabolic risk factors and macrovascular disease

As in most parts of the world, diabetes in Saudi people is mainly type $2,{ }^{17,18}$ clustering with obesity, dyslipidemia and other variables of the insulin resistance syn- drome. ${ }^{5,6,12,13}$ Dramatic changes in lifestyle with resultant obesity and possible genetic predisposition are probably responsible for the diabetes epidemic in Saudis, which is akin to other populations who witnessed similar changes. ${ }^{34} \mathrm{~A}$ possible interaction of high consanguinity rate to familial aggregation has been suggested..$^{35}$

Among Saudis, glucose intolerance is a major risk factor for vascular events, ${ }^{36}$ especially cerebrovascular disease $^{37}$ and myocardial infarction, ${ }^{38}$ and especially in young patients. ${ }^{39}$ In one study, diabetes was a predictor of acute myocardial infarction in patients attending primary health care centers. ${ }^{40}$ Obesity and being overweight are major variables of the insulin resistance syndrome in Saudi Arabs and are strongly linked to type 2 diabetes. The diabetes epidemic has paralleled the upsurge of obesity in Saudis. El-Hazmi and Warsy studied the prevalence of obesity among 1419 patients with diabetes and 13241 non-diabetic subjects from different regions of Saudi Arabia. They found that obesity $\left(\right.$ BMI $\left.>29 \mathrm{~kg} / \mathrm{m}^{2}\right)$ and overweight (BMI $25-29 \mathrm{~kg} / \mathrm{m}^{2}$ ) is present in $30 \%$ and $33 \%$ of those with diabetes but only in $16 \%$ and $25 \%$ of those without diabetes, respectively. ${ }^{13}$ In the report by Al-Nuaim, (1997) diabetes and impaired glucose tolerance were increased in those who were overweight or obese, ${ }^{14}$ with impaired glucose tolerance more common in overweight males and diabetes more common in overweight and obese females. In that study the overall prevalence of overweight and obesity in either sex exceeded $60 \%$, which is one of the highest rates in the world..$^{41}$ In another study, only $19 \%$ of diabetic and hypertensive patients attending primary care services were within their ideal body weight, and only $9 \%$ of females had a BMI $<25 \mathrm{~kg} / \mathrm{m}^{2} .42$

Recently, AlHarthy and AlGhamdi, (2005) reported a significant relationship between serum resistin, a possible marker of insulin resistance, and all indices of body weight in diabetic and non-diabetic female Saudi women, implying that overweight Saudi females are at high risk of developing diabetes. ${ }^{43}$ Furthermore, Aldaghri et al (2005) showed that serum resistin is related to both LDL and CRP, providing a possible link between insulin resistance, hyperlipidemia and inflammation. ${ }^{44}$

Hypertension is linked with diabetes in Saudis; however, the strength of its relationship seems to be conflicting. Akber found that hypertension was present in $60 \%$ of the 427 patients with diabetes who were admitted to hospital, ${ }^{45}$ and this is strongly linked with other cardiovascular complications, renal failure and higher mortality. However, Warsy and el-Hazmi (1999), in their epidemiological survey, reported that hypertension was present in $5.4 \%$ of males and $3.7 \%$ of females. ${ }^{46}$ The difference between the two studies is likely related to selec- 
tion bias and the small number of patients in the earlier study. Their finding is confirmed by Al-Shammari et al (1994). ${ }^{47}$

In the study by Al-Nuaim (1997), lipoprotein abnormalities were common in diabetic Saudis with high numbers in the 90th centile of serum total cholesterol concentration across the various age groups, but was less severe than their age- and sex-matched European counterparts. ${ }^{36}$ Of the study cohort, 50\% had low HDL and this was associated with overweight or obesity. High triglycerides were found mainly in males with glucose intolerance and to a lesser extent in females, despite the females having higher BMI. The combination of low HDL and high TG reflects the atherogenic lipoprotein phenotype in Saudis as a refection of insulin resistance.

Among patients with stroke, $37 \%$ to $41 \%$ have diabetes $^{48,49}$ and diabetes is a major risk factor among patients admitted to the hospital with stroke disease. Diabetes also contributes to morbidity, mortality and long hospital stay. ${ }^{50}$ Young Saudi diabetics are more prone to lacunar cerebral infarct, ${ }^{51}$ Furthermore, diabetes was shown to be a major contributor to peripheral artery disease in Saudis with $61 \%$ of those with diabetes having peripheral artery disease. ${ }^{52}$ On the other hand, diabetes is a well documented predictor of coronary artery thrombosis in patients in primary care, ${ }^{40}$ despite the fact that to date no study has assessed the prevalence and severity of coronary artery disease in Saudi patients with diabetes.

The study by Al-Nozha et al (2002) assessed the level of homocysteine, the independent vascular risk factor, and found that it is lower in Saudi diabetic patients, ${ }^{53}$ in contrast to the study by Ajabnoor et al. ${ }^{54}$ Interestingly, Ajabnoor et al showed a linear relationship between LDL and homocysteine, an observation documented before in young menstruating Caucasian females. ${ }^{55}$ More data is needed to resolve this disparity. C-reactive protein (CRP), a surrogate for inflammation and excess vascular risk was reported to be reduced by metformin but not by glibenclamide in a group of Saudi patients with type 2 diabetes. ${ }^{56}$

\section{Diabetic retinopatby}

Among Saudi patients, the prevalence of retinopathy is $31 \%$ after a mean duration of diabetes greater than 10 years. ${ }^{57}$ This is in keeping with data from the Diabetes Control and Complications Trial involving type 1 diabetes patients from the USA as well as data from the United Kingdom involving type 2 diabetes patients. ${ }^{58,59}$ The duration of diabetes and the incidence and severity of retinopathy are closely associated. ${ }^{57}$ In patients with type 1 diabetes, the incidence rose from $6.1 \%$ in those with diabetes duration $\leq 5$ years, to $62 \%$ in those who had the disease for $\geq 10$ years. For persons with type 2 diabetes the incidence rose from $10 \%$ to $50 \%$ for those with a similar duration of diabetes. No proliferative retinopathy was seen amongst type 1 diabetes patients with disease duration $\leq 5$ years and only in $0.8 \%$ of those with type 2 diabetes. In those with disease duration $\geq 10$ years, $9 \%$ of those with type 1 diabetes and only $2.1 \%$ of persons with type 2 diabetes had proliferative retinopathy. Insulin use is a significant factor associated with the incidence of retinopathy and in those with type 1 diabetes who had an increased incidence and severity of retinopathy compared to persons with type 2 diabetes ( $43 \%$ and $6 \%$ vs. $25 \%$ and $1.5 \%$, respectively). In addition to longer diabetes duration, poor glycemic control, hypertension and raised serum cholesterol are the main risk factors for development of retinopathy in all groups. The presence of nephropathy correlated with severity in all age groups. In another study by the same group, ${ }^{60}$ the presence of retinopathy was a strong predictor for the presence of other diabetic complications in both type 1 and type 2 diabetes patients. Among 90 patients with retinal vein occlusion, $31 \%$ had diabetes and in nearly one third the occlusion was attributed to intense dehydration whilst fasting during the wholly month of Ramadan. ${ }^{61}$ In summary, data on diabetic retinopathy in Saudi patients, albeit scarce, seems to be in agreement with data from other parts of the world. However, to date no study has examined screening strategies for diabetic retinopathy in Saudi patients.

\section{Diabetic neuropathy and foot disease}

Preliminary data from the Western part of Saudi Arabia suggests that the overall prevalence of neuropathy in diabetic patient is $82 \%$, which is one of the highest in the world. ${ }^{62}$ Among those with neuropathy, 57\% were asymptomatic, implying subclinical disease, and symptomatic disease is related to old age, longer duration of diabetes, poor diabetes control, type 2 diabetes and smoking. On the other hand, a study by Fonseca et al found relatively common abnormalities in tests of autonomic nerve dysfunction in a group of patents who had a relatively short duration of diabetes, implying a longer duration of subclinical diabetes in Saudi Arabs. ${ }^{63}$ The same group confirmed their earlier finding by documenting prolonged cardiac systolic time, a surrogate for cardiac autonomic neuropathy ${ }^{64}$ In a comparative study between a group of Swedish patients with diabetes and similar age- and sex-matched Saudi patients, Neilsen (1998) found that the prevalence of diabetic neuropathy was similar in both groups. ${ }^{65}$ However, the occurrence of foot ulcers and the amputation rate was significantly 
lower in the Saudi group. These findings were similar to a recent report by Abbott et al (2005) on the lower prevalence neuropathy and foot complications in Asians and Afro-Caribbeans compared to Caucasian diabetic patients in the UK. ${ }^{66}$

Qidawi et al (2001) reported that 29\% of Saudi patients with diabetic peripheral neuropathy have some features suggestive of diabetic neuroarthropathy, and that $18 \%$ of those patients underwent foot amputations. ${ }^{67}$ In a study by Akbar and Qari (2000), which looked exclusively into diabetic foot lesions in Saudi diabetics, but involved a small number of patients, found that the problem is mainly seen in males, and that $23.5 \%$ ended with major amputations. ${ }^{68}$

Erectile dysfunction in patients with diabetes is primarily related to neurovascular dysfunction. In a study by El-Sakka and Tayeb, a high prevalence of erectile dysfunction is reported among their study cohort of Saudi patients with type 2 diabetes, but other confounding factors like other endocrine disease and use of various medications may have overestimated their finding. ${ }^{69} \mathrm{Al}$ Helali et al studied 388 patients with erectile dysfunction and found that $30 \%$ of them had diabetes ${ }^{70}$ Management of these patients is hampered by several economic, social and educational factors. ${ }^{71}$

\section{Diabetic nephropathy}

There is a global increase in the scale of diabetic chronic kidney disease with a resultant increase in those requiring renal replacement therapy, in the aftermath of the diabetes pandemic worldwide. Saudi Arabia is no exception. Despite that data on diabetic nephropathy in Saudi are scarce, ${ }^{72}$ diabetes is responsible for $30 \%$ to $45 \%$ of those requiring dialysis. ${ }^{73}$ Al-Zaid et al (1994) screened 211 patients with type 2 diabetes for microalbuminuria (MA) and found that $41.3 \%$ had MA and $12.8 \%$ had dipstick positive proteinuria. The subjects with MA had higher fasting blood glucose and BMI, but there was no difference in the levels of total cholesterol, the presence of hypertension or length of diabetes duration between those with and those without MA. ${ }^{74}$ No follow-up data is available from this study, nor is there to date any data on patients with type 1 diabetes. Furthermore, MA in type 2 diabetes may represent a marker of vascular dysfunction and vascular risk rather than an exclusive indication of future development of diabetic end-stage real disease (ESRD).

In a case-notes review study, Al-Hamrany and Abdelmoniem (2004) examined 208 patients with type 2 diabetes attending primary care services in the southern region. Dipstick positive proteinuria was found in
$54 \%$ of patients and this was associated with poor diabetes control and dyslipidemia ${ }^{75}$ However, this study had several limitations, including ascertainment bias of those with proteinuria, and methods of assessing overall glycemic control. In Caucasians with diabetic microalbuminuria, $20 \%$ to $40 \%$ develop overt nephropathy in 6 years, compared to $37 \%$ to $40 \%$ of Pima Indians with MA over a 4 to 5 year period. ${ }^{76}$ Preliminary data from Saudi Arabia is in accord with the latter. ${ }^{72}$

In a study involving a small number of patients, $\mathrm{Al}$ Khader (2001) followed up 28 patients with type 2 diabetes and diabetic nephropathy (confirmed by renal biopsy) and found that $43 \%$ became dialysis dependent, $42 \%$ doubled their creatinine and only $15 \%$ had a stable course. ${ }^{72}$ This confirms that the rate of progression of diabetic nephropathy in Saudi patients is alarmingly fast when compared with data reported from Pima Indians. ${ }^{76}$ The dialysis population in Saudi Arabia has grown from only 370 patients in early 1980 s to 7020 patients in the late $1990 \mathrm{~s},{ }^{77}$ and the number of diabetic patients entering renal replacement therapy rose from $4 \%$ in early 1980 s to $14.8 \%$ in the mid $1990 \mathrm{~s}^{78}$ to $40 \%$ in the late 1990 s. $^{79}$ The majority of those are type 2 diabetic patients. Furthermore, mortality among those entering dialysis has increased significantly, with the majority of deaths $(60 \%)$ among those with diabetes.

There is also a parallel rise in incidence of hepatitis $\mathrm{C}$ infection among the dialysis population, ${ }^{77}$ and this has a special predilection for patients with diabetes ${ }^{80}$ In a study by Souqqiyyeh et al (1996), involving a group of patients who underwent renal transplantation in two major transplant centers in Saudi Arabia, and who were followed up between 1985-1996, 12.1\% developed post-transplant diabetes (PTD) after a mean followup period of 67 months vs. PTD in $10 \%$ among those who had diabetes pre-transplant. ${ }^{81}$ This rate of PTD development is similar to the rate reported from other countries. ${ }^{82}$ The major risk factor for PTD is increasing age, but other important risk factors like family history and HLA haplotype were not ascertained. Another weakness of the study is that the follow-up was prior to the widespread use of immunosuppressants, which have a major causative role in PTD. Despite that the rate of PTD is similar to the rate in the background population in earlier studies., ${ }^{5,12}$ Further studies are needed as this study involved only two centers, and the current scale of PTD needs to be ascertained, especially with the recent dramatic increase in diabetes prevalence in the background population as well as the increase in those with diabetic ESRD who are increasingly receiving renal transplant. 


\section{Special Features of Diabetes in Saudi Arabia}

High rate of consanguineous marriage in Saudi people Saudi Arabia has one of the highest rates of consanguineous marriage in the world. In a study by el-Hazemi et al the rate of consanguinity is reported as high as $57.7 \%$, with first cousin marriage being $28.4 \%$ followed by distant relative marriage at $14.6 \%{ }^{7}$ Such a high rate of consanguinity may have a special impact on a polygenic disease like diabetes mellitus, especially type 2 diabetes. Anokute, in a retrospective study of 210 cases of diabetes in the central region of Saudi, found that familial aggregation yielded an odds ratio of $6: 2$, which suggests a causal association with diabetes. ${ }^{82}$ However, the number in this analysis was small, and a larger epidemiological analysis did not include this variable for analysis. One may speculate that the high consanguinity rate has a special impact on type 2 diabetes in Saudis, but the confirmation of this will await analysis involving a large number of patients. Interestingly, the impact of consanguinity is well known on inherited monogenic diseases like thalassemia and glucose-6-phosphate dehydrogenase deficiency (G6PD), and those conditions amplify diabetes in affected subjects (see below).

\section{Hemoglobinopathies and diabetes}

Patients with hemoglobinopathies such as sickle cell disease and thalassaemia may be especially prone to develop secondary diabetes following repeated blood transfusion with subsequent hemosiderosis and liver and pancreatic damage. Hemoglobinopathies are common in the Saudi population, especially in those in the Eastern province ${ }^{83}$ where the prevalence of diabetes has been reported to be the highest in the Kingdom. ${ }^{5}$ Diabetes among children with thalassemia is higher than in their Caucasian counterpart. ${ }^{22}$ No study has assessed the prevalence of diabetes among children with sickle cell syndrome who are also prone to develop secondary diabetes. On the other hand, Niazi (1991) has demonstrated a high prevalence of G6PD deficiency among Saudi diabetic patients $-12.4 \%$ vs. $2 \%$ in healthy non-diabetic control subjects. ${ }^{84}$ The clinical significance of this association is not clear.

\section{Ramadan fasting and diabetes}

Saudi Arabia is an exclusively Muslim country, and fasting during Ramadan has a special impact on diabetes. ${ }^{85}$ There is a growing body of literature on the relationship between fasting during the Holy month of Ramadan and diabetes, with fasting reported to be beneficial in patients with type 2 diabetes, ${ }^{86}$ but potentially harmful in elderly patients, and those who are ketosis prone, and in those who have advanced complications. ${ }^{87,88}$ Only one paper has examined the impact of Ramadan fasting on Saudi type 2 diabetic patients, ${ }^{89}$ with no reported change in the level of fasting glucose, glycated hemoglobin, insulin, C-peptide or body weight, and with a significant rise in total cholesterol, but not triglycerides, at the end of fasting. It is an irony that the perceived benefit from fasting will require specific education and advice to patients and such education seems to be very much deficient or none existent. ${ }^{90}$ Dehydration during Ramadan fasting may be a trigger for retinal vein occlusion in patients with diabetes. ${ }^{61}$ Therefore, the need for more research in this area is needed, ${ }^{88}$ especially for other rituals during Ramadan, like Umra, which may have special impact on diabetes and its complications (Elhadd et al, unpublished observations).

\section{The Muslim Pilgrimage (Haji) and diabetes}

Every year there is a massive gathering of several million Muslims in the Holy places of Mecca and Medina. Among such pilgrims are many diabetic patients, and in general the provision of medical care to such patients is a challenging exercise. AlGhamdi et al (2003) ${ }^{91}$ have shown that diabetes is a major co-morbid condition among those pilgrims, and that admission with medical emergencies is modified by the season of the ritual (Hajj follows a lunar calendar and it changes by approximately 11 to 12 days every year). We have recently observed that Hajj has an impact on patients with diabetes because significant numbers present to emergency medical care centers with infected foot ulcers, hyperglycemia and infections (Elhadd et al, unpublished observations).

\section{Infections and diabetes}

Patients with diabetes, in general, are more susceptible to various types of infection. Saudi diabetic patients are more prone to infection with Mycobacterium tuberculosis, and to viral hepatitis infections. Saudi patients with diabetes and ESRD on hemodialysis are more likely to contract hepatitis $\mathrm{C}$ infection than those without diabetes. ${ }^{92}$ Conversely, patients with hepatitis $C$ infection have a special predilection to develop diabetes. The interplay of various factors, including the genetic susceptibility, may amplify such risk further. Akbar et al (2002) have shown that Saudi patients with hepatitis $C$ infection who develop diabetes are more likely to have a higher BMI and a positive family history of diabetes. ${ }^{93}$ As patients with hepatitis A infection do not develop chronic hepatic sequelae, Makeen (1992) reported acute development of diabetes in three Saudi subjects with hepatitis A infection, with clinical and biochemical evidence of acute insulin deficiency (arguably resulting from pancreatic 
involvement and possibly acute islitis) culminating in diabetic ketoacidosis. ${ }^{94}$ Despite no follow-up data from this case series, a similar report from Nigeria showed diabetes to remit in six patients following acute hepatitis A infection, which recurred later in four patients. ${ }^{95}$

Mycobacterium tuberculosis, both pulmonary and extra-pulmonary, is on the rise in Saudi Arabia, and diabetes is a major risk factor for developing pulmonary, ${ }^{96}$ as well as disseminated tuberculosis. ${ }^{97}$ Nearly half of dialysis patients who had tuberculosis suffer from diabetes. ${ }^{98}$

\section{Herbal medicine use by Saudi diabetics}

Use of herbal medicines to treat various diseases is wellrecognized practice in both developing and developed countries. In Saudi Arabia, however, the use of herbal medicine by diabetic patients seems to be high. In one study, $17 \%$ of a cohort of 296 patients from several diabetic clinics reported using herbal medicines without informing their physicians. ${ }^{99}$ In another study by Al-Saeedi et al (2003) one-third of a cohort of 1039 patients with diabetes were using herbal medicine, and $25 \%$ of them believed that it is both safe and effective. ${ }^{100}$ In this study, such a belief correlated with female sex, a family history of diabetes and poor compliance with diet. A study by Bugusz et al showed that herbal medicines may contain toxic materials. ${ }^{101}$

\section{Conclusion}

Data accumulating over the last three decades have confirmed that there is an epidemic of type 2 diabetes in Saudi Arabia. There is evidence to suggest that this has resulted from significant socioeconomic transformation with significant changes in lifestyle, mainly adoption of a Western lifestyle and abandonment of the more active tribal and nomadic-type of life. The concomitant upsurge of the epidemic of obesity is another irony of these changes. Diabetes in Saudi Arabia is well researched, especially in its epidemiology and clinical aspects. However, with few exceptions, the profile of diabetic complications needs to be better characterized. The rate of development and progression of diabetic nephropathy appears to be comparatively fast, so contributory factors needs to be explored. Also despite the high level of evidence for more severe atherosclerotic disease especially affecting young patients, more studies are needed, particularly in patients with diabetic coronary artery disease. Further, the genetics of diabetes needs to be studied, as significant genetic susceptibility is probably a major player in the diabetes pandemic. The high consanguinity rate may help to give new insights into the genetics of type 2 diabetes in general. In this regard, the possibility of new subtypes of maturity-onset diabetes of youth may be unraveled. Finally, there is a need for studies looking into models of organization of care, screening for early complications and patient education and empowerment. Measures to curb the rising rates of obesity need also to be rigorous.

The authors would like to thank Dr. Naser Alulagi for his belp with the section on diabetic nephropathy. Special thanks to Mr. Faroug Ali Aijaz for his invaluable secretarial belp, and to Miss Arwa Shaza Elhadd for her help with the references section. Thanks are also extended to Drs Bill Kelly, Rudi Bilous and Rayaz Malik for their useful comments. 


\section{REFERENCES}

1. Amos A, McCarthy D, Zimmit P. The rising globa burden of diabetes and its complications: Estimates and projections to the year 2010. Diabet Med 1997; 14(S1-S85).

2. Wild S, Roglic G, Green A, Sicree R, King H. Global prevalence of diabetes estimates for the year 2000 and projection for 2030. Diabetes Care 2004; 27(5):1047-53

3. Ledward RS. Initial findings in a new obstetric unit in Saudi Arabia. Trop Doct 1982; 12(2):63.

4. Bacchus RA, Bell JR, Madkour M, Kilshaw. The prevalence of diabetes mellitus in male Saudi Arabs. Diabetologia 1982; 23(4):330.

5. Al-Nuaim AR. Prevalence of glucose intolerance in urban and rural communities of Saudi Arabia. Diabet Med 1997; 14(7):595-602

6. Al-Nozha MM, Al-Matouq MA, Al-Mazrou YY et al. Diabetes in Saudi Arabia. Saudi Med J 2004; 25(11): 1603-10

7. el-Hazmi MA, al-Swailem AR, Warsy SA, alSwailem AM, Sulimani R. al-Mashari AA. Consanguinity among Saudi Arabian population. J Med Genetics 1995; 32(8):623.

8. Cook GC. Rapid glucose absorption in Arabs in Saudi Arabia compared in that in Africans in Zambia. Br Med J 1976; 201(6011):688-89.

9. Gupta OP, Joshi MH, Dave SK. Prevalence of diabetes mellitus in India. Adv Metabol Disord 1978; 9:147-65.

10. Fatani $\mathrm{HH}$. Prevalence of diabetes mellitus in rural Saudi Arabia. Diabetes Care 1987; 10(2):180.

11. Anukote CC. Epidemiology studies of diabetes mellitus in Saudi Arabia-Part 1-screening of 3158 males in King Saud University. J Soc Health 1990; 110(6):210-03

12. el-Hazmi MA, Warsy AS, al-Swailem AR, alSwailem AM, Sulimani R., Al Meshari AA. Diabetes mellitus and impaired glucose tolerance in Saud Arabia Annals Saudi Med 1996 ; 16(4):381-385 13. el-Hazmi MA, Warsy AS. Prevalence of overweight and obesity in diabetic and non-diabetic Saudi Arabians. East Mediterr Health J. 2000; 6(2 3):276-82.

14. Al- Nuaim RA. Effects of overweight and obesity on glucose intolerance and dyslipidemia in Saud Arabia: an epidemiological study. Diabet Res Clin Pract 1997; 36(3):181-91

15. Salman $H$, Abanamy A, Ghassan B, Khalil M. Childhood diabetes in Saudi Arabia. Diabet Med 1991; 8(2):176.

16. Kulyalat NA, Narchi H. A twelve year study of the incidence of childhood Type-1 diabetes mellitus in the Eastern Province of Saudi Arabia. J Ped Endocrinol Metabol 2000; 13(2):135-40

17. Fonseca V, Laajam MA, Tongia RK. Non-ketotic diabetes mellitus in young non obese Saudi Arabians. East Afr Med J 1985; 62(1):21-25.

18. Famuyiwa 00 , Sulimani RA, Laajam MA, AlJasser SJ, Mekki MO. Diabetes mellitus in Saud Arabia: the clinical pattern and complications in 1000 patients. Ann Saudi Med 1992; 12:140-51.

19. Alhussein KA, Rama NR, Ahmed M, Rozemulla E. HLA-DPBI0401 is associated with dominant pro tection against Type-1 diabetes in general Saud population in subjects with risk DR/DQ haplotype. Eur J Immunogenet 2003; 36(2)115.

20. Abdullah MA, Salman H, Bahakim H, Gad al Rab MO, Halim K, Abanmy A. Antithyroid and other organ-specific antibodies in Saudi Arab diabetic and normal children. Diabet Med 1990; 7(1):50-52.

21. Oari F, Damnan S. Schmidt's syndrome in a Saudi family. Saudi Med J 2000; 21(1):93-95

21. el-Hazmi MA, al-Swailem AR, al-Fawaz I, Warsy AS, al-Swailem AM. Diabetes mellitus in children suffering from beta thalssemia. J Trop Pediatr 1994; 40(5):261.
23. Taha D, Barbar M, Kanaan, Williamson Balfe J. Neonatal diabetes mellitus, congenital hypothyroidism, hepatic fibrosis, polycystic kidneys and congenital glaucoma: a new autosomal recessive syndrome. Am J Med Genet 2003; 122A (3):269.

24. Woodhouse NJ, Sakatti N. A syndrome of hypogonadism, alopecia, diabetes mellitus, menta retardation, deafness and ECG abnormalities. J Med Genet 1983; 20(3): 216

25. AlShawaf T, Akeil A, Mograby SA. Gestationa diabetes and impaired glucose tolerance in Riyadh. Br J Obstet Gyanecol 1988; (1):84-90.

26. Mwambingen FT, Al Meshari AA, Akeil A. The problem of grandmultiparity in current obstetric practice. Int J Obstet Gynaecol 1988; 26(3):355.

27. Khawja SS, AlSuleiman SA al-Sibai $\mathrm{MH}$ Screening for gestational diabetes in a teaching hospital in Saudi Arabia. Aust N Z Obstet Gynaecol 1989; 29(3pt1):209-11

28. al-Teheawy MM. Prenatal care in primary health care centres of Al-Hassa, Saudi Arabia. J Egypt Public Health Assoc 1992; 67(1-2 PubMed : $37-51$.

29. Nasrat $H A$, Salih $M$, Ardawi $M$, Ghafouri $H$. Outcome of pregnany in diabetic mothers. Into $J$ Gynaecol Obstet 1993; 10(8):29.

30. Nasrat HA, Fageeh W, Abalkail B, Yamani $T$ Ardawi M. Determinant of pregnancy outcome in patients with gestational diabetes. Int J Gynaecol Obstet 1996; 53(2):117.

31. Subande AA, Al-Bar A, Archibong EL. Diabetes and perinatal loss. A continuing problem. Saudi Med J 2000; 21(2):161-63.

32. El Mallah KO, Narch H, Kulyate NA, Shaban MS Gestational and pregestational diabetes. Comparison of maternal characteristics and outcome. Int J Gynaecol Obstet 1997; 58(2):203.

33. Narchi H, Kulaylat NA, High incidence of Down's Syndrome in infants of diabetic mothers. Arch Dis Child 1997; 77(3):242.

34. O'Dea K. Westernization and non-insulin dependent diabetes in Australian aborigines. Ethn Dis 1991; 1(2):171-187.

35. Anokute CC. Suspected synergism between consanguinity and familial aggregation in type-2 diabetes in Saudi Arabia. J R Soc Health 1992; 112(4):167.

36. AINuaim A. High prevalence of metabolic risk factors for cardiovascular diseases among Saudi population aged 30-64 years. Int J Cardiol 1997; 62(3):227

37. AlRajeh A, Awada A. Stroke in Saudi Arabia Cerebrovasc Dis 2002; 13(1):3.

38. Osman AK, Al-Nozha MM. Risk factors of coronary artery disease in different regions of Saud Arabia East Mediterr Health J. 2000; 6(2-3):465-74. 39. AlKhadra AH. Clinical profile of young patients with acute myocardial infraction in Saudi Arabia. In J Cardiol 2003; 91(1):9.

40. .Alhumaidi MA. Probability of coronary artery disease among patients attending primary health care centres in southwest Saudi Arabia. Ethn Dis 2000; 10(3):350.

41. Kuskowska X, Wolk A, Rossners Y. Prevalence of overweight in Sweden: a cross-sectional study of representative world population. J Int Med 1990; 227: 241-246 PubMed.

42. Al-Turki YA. The prevalence of overweight and obesity amongst hypertensive and diabetic adult patients in primary health care. Saudi Med J 2000; 21(4):340-43.

43. Al Harithy RN, Al Ghamdi S. Serum resistin, adiposity and insulin resistance in Saudi women with type-2 diabetes. Ann Saudi Med 2005; 25(4):283.

44. Aldahgri N, Chetty R, McTerran PG, Al-Rubean K, Al-Attas 0, Jones A, Kumar S. Serum resistin is associated with C-reactive protein \& LDL cholesterol in type-2 diabetes and coronary artery disease in Saudi population. Cardiovasc Diabetol 2005; 4(1):10-14

45. Akbar DH. Is hypertension common in hospitalized type-2 diabetic patients? Saudi Med J 2001; 22(2):139-41.

46. Warsy AS, el-Hazmi MA. Diabetes mellitus, hypertension and obesity: common multifactorial disorders in Saudi East Meditter Health J 1999; 5(6):1236-42.

47. Al-Shammari SA, Ali M, al-Shammari $A$, alMaatoug M, Tennier A, Armstrong K. Blood lipid concentration and other cardiovascular risk factors among Saudi's. Fam Pract 1994; 11(2):153-58.

48. AlRajih S, Larbi EB, Bademosi 0 et al. Stroke egister: experience from the Eastern Province of Saudi Arabia. Cerebrovasc Dis 1998; 8(2):86. 48. Awada A, Al Rajeh S. The Saudi stroke data bank. Analysis of the first 1000 cases. Acta Neurol Scand 1999; 100(4):265-69.

50. Qari FA. Profile of stroke in a teaching university hospital in the Western region. Saudi Med J 2000; 11:1030-33.

51. AlRajeh S, Awada A. Stroke in Saudi Arabia. Cerebrovasc Dis 2002; 13(1):3 PubMed -8

52. Al Zahrani HA. The distribution of peripheral arterial disease in a defined population of elderly high risk Saudi patients. Int Angiol 1997; 16(2):123.

53. AlNozha M, Aldaghri N, Bartlett WA et al. Serum homocysteine concentration is related to diabetes mellitus but not to coronary artery disease in Saudi Arabia. Diabetes Ob Metab 2002; 4(2):118-23.

54. Ajabnoor MA, Al-Ama MN, Banjar Z, Rafee AA, Sheweita SA. Homocysteine levels and other biochemical parameters of cardiovascular disease in patients with diabetes, Med Sci Monit 2003; 9(12): CR523.

55. Elhadd TA, Neary R, Abdu TA et al. Influence of hormonal changes during the normal menstrual cycle in young healthy women on soluble adhesion molecules, plasma homocysteine, free radical markers and lipoprotein fractions. Int Angiol 2004; 22(3):222.

56. Akbar DH. The Effect of metformin and sulphonylurea on c-reactive protein in well controlled patients with type-2 diabetes with metabolic syndrome. Endocrine 2003; 20(3):215.

57. Abu El Asrar AM, Al-Rubean KA, Al-Amro SA, Kangave D. Risk factors for diabetic retinopathy among Saudi diabetics. Int Ophthalmol 1998-1999; 22(3 PubMed):155-61.

58. The Diabetes Control and Complication Trial Research Group. The effect of intensive treatment of diabetes on the development and progression of long-term complications of IDDM. New Eng J Med 1993; 329:877-986

59. UK Prospective Diabetes Study Group. Intensive blood glucose control with sulphonylurea or insulin compared with conventional treatment and risk of complications in patients with type-2 diabetes. Lancet 1998; 12; 352(9131 PubMed):837-53.

60. Abu El Asrar AM, Al-Rubean KA, Al-Amro SA, Moharam $0 A$, Kangave D. Retinopathy as a predictor for other diabetic complications. Int Ophthalmol 2001; 24(1):1

61. Alghadyan AA. Retinal vein occlusion in Saudi Arabia. Possible role of dehydration. Ann Ophthalmol 1993; 25(10):394-98.

62. Akbar DH, Mira SA, Zawawi TH, Malibary HM.Subclinical neuropathy a common complication in Saudidiabetics. Saudi Med J 2000; 21(5):43337.

63. Fonseca V, Laajam MA, Tongia RK. Asymptomatic autonomic neuropathy in Saudi diabetics. Saudi Med J 1985; 6(1):38-42. 
64. Tongia RK, Fonseca V, Laajam MA. Abnorma systolic time interval in asymptomatic Saudi diabetics. Saudi Med J 1984: 5:415-20.

65. Neilsen JV. Peripheral neuropathy, hypertension, foot ulcers and amputations among Saudi Arabian patients with Type-2 diabetes. Diabetes Res Clin Pract 1998; 41(1):63-69.

66. Abbott CA, Garrow AP, Morris J, Van Ross ER Boulton AJ. North-West diabetes foot care study. Foot ulcer risk is lower in South Asian and Afro-Caribbean compared with Europeans patients in UK. Diabetes Care 2005; 28(8):1869 PubMed -75.

67. al Oidawi SA, Khan MA, Hussein SR, Malik MS. Diabetic neuroarthropathy Saudi Med J 2001; 22(2):42-47

68. Oari FA, Akbar DH. Diabetic foot presentation and treatment. Saudi Med J 2000; 21(5):443-46 69. El Sakka AL, Tayeb KA. Erectile dysfunction risk factors in non-insulin dependent diabetic Saudi patients. J Urol 2003; 169(3):1043.

70. Al Helali NS, Abolfotouh MA, Ghanem HM. Pattern of erectile dysfunction in Jeddah city. Saudi Med J 2001; 22(1):34-8

71. Onuora VC, Koko AH, Patil MG. Management of impotence in a developing country. East African Med J 1995; 72(7):415-57

72. Al Khader AA. Impact of diabetes on renal disease in Saudi Arabia. Nephrol Dialysis Transplant 2001; $16: 2132-35$

73. Mitwalli A, Al-Swailem AR, Aziz KMS et al. Etiology of end stage renal disease in two regions of Saudi Arabia.Saudi J Kidney Dis Transplant 1997; 6(1):16-20.

74. AlZaid A, Sobki S, De Silva V. Prevalence of microalbuminuria in Saudi Arabian with non-insulin dependent diabetes: a clinic based study. Diabetes Res Clin Pract 1994; 26:115-120

75. Al-Homrany MA, Abdelmoneim I. Significance of proteinuria in type-2 diabetic patients treated a a primary health care centre in Abha City, Saud Arabia. West Afr J Med 2004; 22(3):211-14.

76. Nelson D, Bennet P, Beck G. Development and progression of renal disease in Pima Indians with NIDDM. N Eng J Med 1996; 335-36.
77. SCOT (Saudi Committee of Organ Transplantation) Annual Report. Kingdom of Saudi Arabia Ministry of Health; 1999.

78. Hussein M, Moeji J, Ronj'leh H, El-Sayed H. Observation in a Saudi Arabian dialysis population over 13 years period. Nephrol Dial Transp 1994 9:1072-76 PubMed.

79. Jondeby M, Delos Santos G, Al Ghamdi A et al Caring for hemodialysis patients: present, past and future. Saudi Med J 2001; 22:199-204.

80. Saxena AK, Panhotra BR. The susceptibility of patients with type-2 diabetes to hepatitis-C virus during long-term haemodialysis. Swiss Med Wkly 2003; 133(45-46 PubMed ):611-18.

81. Souqiyyeh M, Shaheen F, Sheikh I et al. Diabetes and renal transplantation: Saudi experience. Saud J Kidney Dis Transplant 2000; 11:25-30 PubMed.

82. Anokute CC. Suspected synergism between consanguinity and familial aggregation of Type2 diabetes in Saudi Arabia. J R Soc Health 1992 112(4):167

83. Alawamy BH. Thalassaemic syndromes in Saudi Arabia: metanalysis of local studies. Saudi Med J 2000; 21(1):8-17.

84. Niazi GA. Glucose 6 phosphate dehydrogenase deficiency and diabetes mellitus. Int $\mathrm{J}$ Haemato 1991; 54(4):295-98.

85. Sulimani RA, Famuyiwa FO, Laajam MA. Diabetes mellitus and Ramadan fasting: the need for critical appraisal. Diabet Med 1988; 5(6):589-91.

86. Uysal AR, Erdogan MF, Sahin G, Kamel N, Erdogan $\mathrm{G}$. Clinical and metabolic effects of fasting in 41 type-2 diabetic patients during Ramadan. Diabetes Care 1998; 31(11):2033.

87. Al-Arouj M, Bouguera R, Buse J, Al-Rubean $\mathrm{KA}$, Hassanien M, Ibrahim $\mathrm{M}$ et al. Recommendation for management of diabetes during Ramadan. Diabetes Care 2005; 28(9): 2305.

88. Elhadd TA, Al-Amoudi AA. Recommendation for management of diabetes during Ramadan. The need for scientific research and patient education. Diabetes Care 2006; 29(3): PubMed 744-45.

89. Lajaam MA. Ramadan fasting and non-insulin dependent diabetes: effect on metabolic control.
East Afr Med J 1990; 67(10):732-36.

90. Elhadd TA, Bissar LS, AlGhamdi SMG, Bashir $\mathrm{M}, \mathrm{Al}$-Amoudi AA. Low education provided to diabetic patients for fasting Ramadan: a questionnaire survey.87th Meeting of American Endocrine Society 2005, San Diego, CA, USA P3-519 (Abstract). 91. AlGhamdi SM, Akbar HO, Oari YA, Fathaldin OA, Al Rashed RS. Patter of admission to hospitals during Muslim pilgrimage (Hajj). Saudi Med J 2003; 24(10):1073-76

92. Saxena AK, Panhotra BR. The susceptibility of patients with type-2 diabetes to hepatitis-C virus during long-term haemodialysis. Swiss Med Wkly 2003; 133(45-46 PubMed):611-16.

93. Akbar DH, Siddique AM, Ahmed MM. Prevalence of type-2 diabetes in patients with hepatitis $C$ and $B$ virus infection in Jeddah, Saudi Arabia. Med Princ Pract 2002; 11(2):82 PubMed -85.

94. Makeen AM. The association of infective hepatitis type A and diabetes mellitus. Trop Geogr Med 1992;44(4):362-64.

95. Oli JM, Nwokolo C. Diabetes after infectious hepatitis: a follow up study. Br Med J 1979; 1(6168):926-27.

96. Al Jahdali H, AlZahrani K, Amene P, Memish Z, AlShemmri A, Moamary M, Alduhaim A. Clinical aspects of military tuberculosis in Saudi adults. Int J Tuberc Lung Dis 2000; 4(3):252-55.

97. Bukhary ZA, AlRajeh AA. Extrapulmonary tuberculosis: clinical presentation and outcome. Saudi Med J 2004; 25(7):881-85.

98. Shohaib S, Scrimgreor E, Shaeyra P. Tuberculosis in active dialysis patients in Jeddah. Am J Neph 1999; 19:34-37.

99. Al Rowis N. Herbal medicine use in treatment of diabetes mellitus. Saudi Med J 2002; 23(1):1327-31. 100. Al Saeedi M, ElZubier AG, Bahnassi AA, AlDawood KM. Pattern and belief and the use of traditional remedies by diabetic patients in Mecca, Saudi Arabia. East Meditter Health J 2003; 9(12):99-107.

101. Bugusz MJ, Al Tufail M, Hassan H. How natural are natural Remedies? A Saudi. Adverse Drug Reaction Toxicology Rev 2002; 21(4):219. 